\title{
An Evaluation into the Role of Online Learning in Enhancing the Delivery of an eBusiness Related Masters Course
}

\author{
Evelyn McLellan and Mark Stansfield \\ University of Paisley, Paisley, Scotland, UK
}

\author{
evelyn.mclellan@paisley.ac.uk mark.stansfield@paisley.ac.uk
}

\begin{abstract}
Within many educational institutions across the world, the delivery of undergraduate and postgraduate courses is being facilitated by online learning technologies. The development and transformation of academic courses for online learning delivery provides a number of opportunities for both the academic institution and prospective students. However, there are a number of important issues that need to be addressed if online learning is to contribute to the educational experience of the student in a positive way and actually enhance teaching and learning as compared with more traditional face-to-face delivery. This paper describes the process of transforming a Masters course in the Management of eBusiness offered by the University of Paisley from a distance learning to an online distance learning course. The paper will identify the main educational theories that informed and influenced the development of the online course as well as identify the main lessons learnt from evaluating the course which has now been running for a number of years. The lessons learnt will be of interest to many people involved in the development and running of online learning courses.
\end{abstract}

Keywords: Online learning, deep learning, strategic learning, eBusiness, learner participation

\section{Introduction}

The MSc Management of eBusiness is an innovative part-time online/distance learning programme offered by the School of Information and Communication Technologies at the University of Paisley. The course provides the skills that modern managers need to understand and manage modern eBusinesses. The course is built on a framework of modules. The modules provide interactive learning through the use of self-assessment questions and multimedia activities and exercises. Each module comprises a number of units, which cover a separate topic of the course. The course offers a range of business, management, IT and eBusiness related modules that enable business managers to fully understand the strategies and technologies that can harness the potential of the Internet and eBusiness. The typical profile of the students taking the course is of a mature graduate in a senior management position within wellknown national and multinational organisations where the role of the Internet and eBusiness is of major strategic importance.

Material published as part of these proceedings, either on-line or in print, is copyrighted by Informing Science. Permission to make digital or paper copy of part or all of these works for personal or classroom use is granted without fee provided that the copies are not made or distributed for profit or commercial advantage AND that copies 1) bear this notice in full and 2) give the full citation on the first page. It is permissible to abstract these works so long as credit is given. To copy in all other cases or to republish or to post on a server or to redistribute to lists requires specific permission from the publisher at Publisher@InformingScience.org
The online distance learning environment has a major contribution to make to the educational requirements of the twenty-first century by encouraging general acceptance of the concept of knowledge as a vital element in social development and economic growth. To keep pace with changes in technology, and to meet the increasing demands of the knowledge-based economy, will require a 
highly-skilled and educated workforce capable of working collaboratively to find solutions to diverse economic, social and environmental problems. The key to success is in large part continuing education, which means that online distance learning, with its open access and opportunities for active collaboration in an egalitarian environment, will have an important role to play in meeting the challenges of the future.

\section{The Process of Learning}

While some students regard the process of learning as simply involving the acquisition of information to be reproduced in an examination room, others experience it as a transforming process which leads to greater personal understanding. Marton and Säljö (1976) identified two differences in the ways that students carried out a reading task which were defined as 'deep' and 'surface' approaches to learning (Säljö, 1979; Entwistle and Ramsden, 1983; Marton et al., 1984).

In the deep approach the student's aim is to understand ideas and relate them to previous knowledge and experience. This involves looking for patterns and underlying principles, as well as critically examining the logic and argument presented. The student shows an active interest in the content of the course. Learning is also viewed as personal development; students feel that the experience of learning has changed them in a personally meaningful fashion. It is more than just understanding what others mean; it has altered their way of seeing a particular aspect of reality. The learning is significant (Grant et al., 2000). It is at this final stage that learning can become an absorbing and exciting process and when students can become genuinely enthused by it. The essence of a deep approach is that students are looking for the point of what is being learned, for links and relationships between ideas, and between the real world. They identify relationships between their own previous understanding and experience. In doing this they do not just reproduce the knowledge, they actively engage with it, subsuming it within their own cognitive order or map. This kind of learning is essentially transformative (Grant et al., 2000). The role of online technology in promoting deep learning was central to the work described in this paper.

By contrast to the deep approach, in the surface approach the student's aim is simply to get through the course without considering its significance. The course is seen as containing unrelated pieces of knowledge which are to be memorised for examination purposes. A consequence of this approach is to create feelings of insecurity in the student and perpetuate a lack of understanding. A third category of approach to learning, namely strategic emerged from the research of Biggs (1979) into how to improve teaching methods. In the strategic approach the object is to obtain the best possible grades. The student's efforts are consistently thorough in pursuit of assessment requirements and work is geared towards perceived preferences of lecturers (Entwistle, 1997).

To foster a deeper approach in students' learning, an approach to teaching and learning was sought that would be likely to produce behaviours associated with a deep (transformative) approach. The next section will explore some of the educational issues associated with online learning that need to be addressed in order to engender deeper approaches to learning.

\section{Educational Issues Involved in Online Learning}

The purpose of this section is to identify and examine the main educational issues that were relevant to and influenced the development of the MSc Management of eBusiness online learning programme.

\section{Lack of Face-to-Face Contact}

The situation of online teachers would appear at first sight to be a difficult one in that they cannot see or hear their students and cannot interact directly with them as in a face-to-face situation. Certainly, online teachers cannot observe their students, cannot see and interpret their facial expressions or note signs of 
inattention and react immediately to rectify matters that may have gone amiss. Feenberg (1998) and Harisim et al., (1995) both make the strongest possible case in favour of online teaching, arguing that the lack of face-to-face contact makes no difference to achieving successful learning and that the quality of online teaching is indeed superior to its face-to-face counterpart.

But certain features of online, as distinct from face-to-face instruction, are educationally adva ntageous such as increased opportunity offered for reflecting on and refining ideas, greater degree of learner control over the materials, flexibility permitted by unrestricted access to the materials and enhanced levels of interaction both in relation to the materials themselves and in the opportunities presented for active learning by means of the conferencing, discussion groups and collaborative learning projects.

\section{Role of the Teacher}

Online learning is student centred and so structured that the course materials are presented in a suitable online format, with learning tasks, collaborative activities and seminar and tutorial conferences being planned by the teacher but not teacher led and directed. The teacher sets the tasks and announces the topic for discussion, but thereafter acts as facilitator rather than classroom lecturer by following the flow of the learner dialogue, offering guidance as necessary and keeping the debate within recognised topic boundaries. The teacher assists with learning by encouraging learners to articulate and elaborate their ideas, by modelling concepts and ideas, fostering learner reflection and by reviewing and providing comments to guide and support learners in the completion of learning exercises.

\section{Role of the Learner}

To take full advantage of the educational opportunities available in the online environment, the learner has to become less of a passive and more of an active participant in the learning process. The online environment offers excellent possibilities for placing students at the centre of learning. Learners are being encouraged to take part in moderating conferences by writing weaving comments and summarising tutorial conference proceedings. They are making valuable contributions to tutorial conferences by enabling a body of knowledge to be built up that reflects their own professional expertise and offers unique insights into topics under discussion. Through active participation learners provide valuable comments and feedback to fellow learners, which enhances learner-to-learner interactivity.

\section{Active Learning}

Online learning requires that learners take an active part in the learning process and participate by posting up their ideas, responding to colleagues and sharing their thoughts and views. Participation requires such intellectual activities on the part of the learner as: formulating initial ideas, considering responses, replying to colleagues' comments and reflecting on ideas in the light of contributions to the discussion. In this way learners go through a cognitive process whereby thoughts and ideas are refined and adapted to take account of other views and perspectives of the original concept. Active participation, with its requirement to formulate and present ideas coherently, enhances the learning process and increases learners' comprehension and retention skills.

\section{Thinking and Reflection}

The online learning environment facilitates a learner-centred approach to learning, with the learner as an active participant in the learning process. The approach requires that teachers help learners to direct their own learning in ways that suit their individual learning styles and preferred methods of working. Creative thinking requires learners to make predictions and hypothesise about situations, as well as to experiment with ideas and communicate results. Learners must research their particular topic thoroughly, 
formulate their ideas and present their findings for peer comment and review. Learners need to explain, with supporting evidence, how conclusions have been arrived at. It is important that learners articulate their findings and solutions clearly and accept that they are open to challenge.

\section{Learner Motivation and Participation}

To encourage and support learning, and preserve motivation, course materials have to be of interest to learners, to ensure that they continue to want to learn. Course materials must be carefully written and structured, with the aim of nurturing the learner's interest in the subject matter so that they feel studying to be valuable and rewarding. The wish to learn has to be strong in online learners because of the high degree of learner control involved and the amount of responsibility that learners take for their own learning in the online environment.

One of the problems facing teachers is the issue of learners not contributing to conferences and tutorials. This may be due to learners feeling anxious about communicating in the conferencing environment or being concerned about their skills in the use of the technology. This is understandable, particularly in view of the uniqueness of the environment, its asynchronous nature and lack of immediate feedback.

\section{Developing a Learning Framework for the MSc Management of eBusiness}

Kolb (1984), in introducing the idea of the experiential learning cycle and of learning styles, defined learning as the process whereby "knowledge is created through the transformation of expertise". This definition embodies the key elements of the experiential approach to learning, namely:

- That learning is a process of adaption and not simply a matter of outcomes.

- That knowledge is a continuous transformation process and not something separately acquired and imparted.

- That knowledge transforms experience both individually and collectively.

- That an understanding of learning requires an understanding of knowledge and the creation of knowledge.

Over the years, researchers have identified a number of cognitive styles, each with its own characteristics. Kolb's Learning Style Inventory comprises four such styles or modes, namely active experimentation, reflective observation, abstract conceptualisation and concrete experience. These styles have been incorporated into the design of the learning tasks that learners complete while progressing through the MSc Management of eBusiness course materials. According to Kolb, learning is a continuous process and in the experiential learning cycle he explains the process of learning as consisting of a four-stage cycle (see Figure 1), each stage of which links into one of the learning modes.

Starting at the top of the cycle, in stage one, the learner has an active experience as a result of which new information is introduced as part of learning. During stage 2 the learning process alters at the observation and reflection stage and here the learner considers and reflects on the active experience of learning of the previous stage. The second stage of the cycle is where the learner reflects, begins to assimilate the new material and to replace it in the context of existing learning to allow an accommodation between the learner's new learning experience and previous learning. Stage three is where the learner considers theories and rules. The learner is required to explore the interrelationships between the old and the new learning experience and to think about and fit the new learning into his/her body of existing ideas and theories. Stage four is where the learner applies the new theories and ideas to the problem solving and having had a successful learning experience, the learner plans the next experience. Having learnt some- 


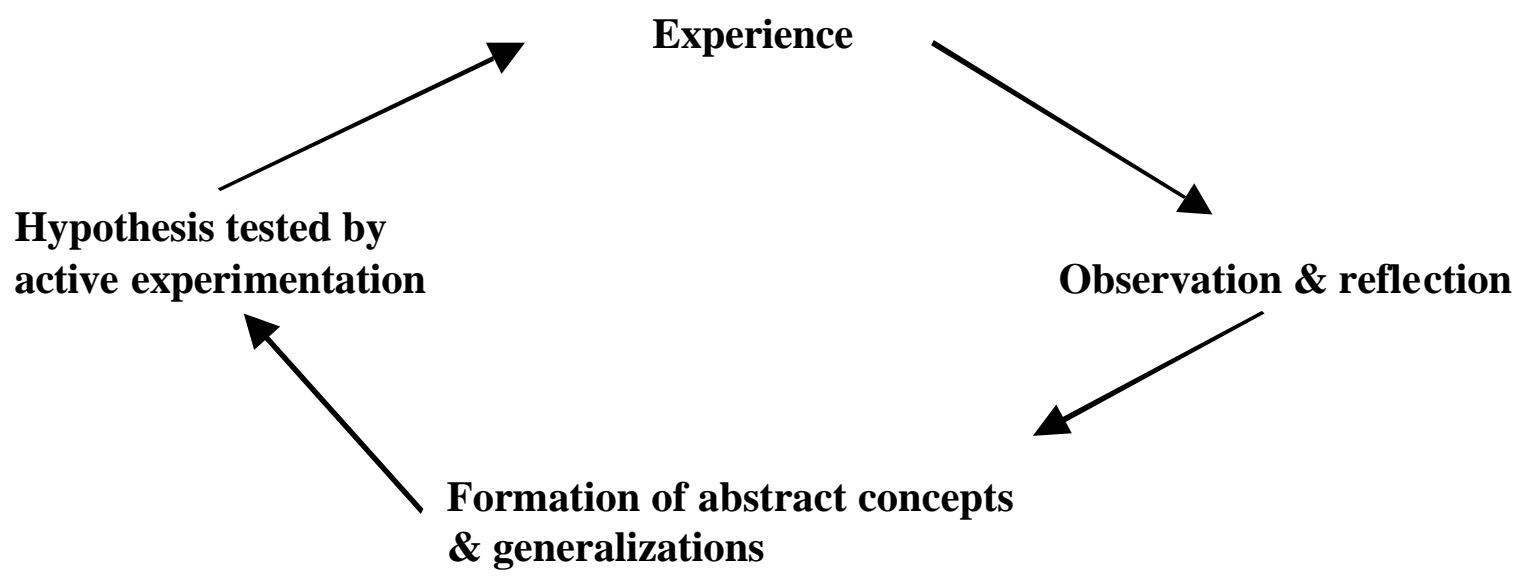

Figure 1: Kolb's four-stage learning cycle

thing new, reflected upon it, assimilated the new learning into existing theory and ideas and put these into practice, the learner moves on to the next learning experience. Kolb (1984) states the combination of all four learning forms produces the highest level of learning by allowing more powerful and adaptive forms of learning to emerge.

The MSc Management of eBusiness was developed around a learning framework that sets out ways in which learners can become more active in their learning and interact with others to enhance and heighten the experience of learning. The following sections will highlight the main areas in the design of the online course that were directed at addressing the key points relating to Kolb's notion of learning.

\section{Online Course Design}

Designing valid learning tasks requires a sound knowledge of both the relevant academic subject matter and, as far as possible, of how learners learn. The learning task is in itself the specification for the ens uing learner activity. The specification of the learning task must be sufficiently detailed to avoid the possibility of the learner engaging in inappropriate or unproductive activity, but should not be so detailed as to stifle a creative response by the learner to completing the task. Learner activity is the process whereby learners interpret the specifications of the learning task and complete the work involved in the task. The designer should specify therefore, in the wording of the learning tasks, exactly what the learner is expected to achieve, the learning activity being the process whereby the learner completes the task. To accomplish the task, learners have to take responsibility for their own learning and decide for themselves how to successfully complete the task. Interpretation of task instructions may in some cases require the learner to take into account previous experience and knowledge to ensure his/her approach is appropriate to the task. Learning outcomes are inextricably linked to the learning tasks, and so the design of educationally valuable learning tasks calls for clarity and precision in the specification of learning outcomes.

A crucial aspect of online course designing is that of creating learning tasks that will enable learning to take place through reflection, collaboration with others and interaction with the learning materials. Since learner engagement with materials is aimed at knowledge building, it follows that the design of learning tasks requires the designer to have a detailed knowledge of the course materials involved. 


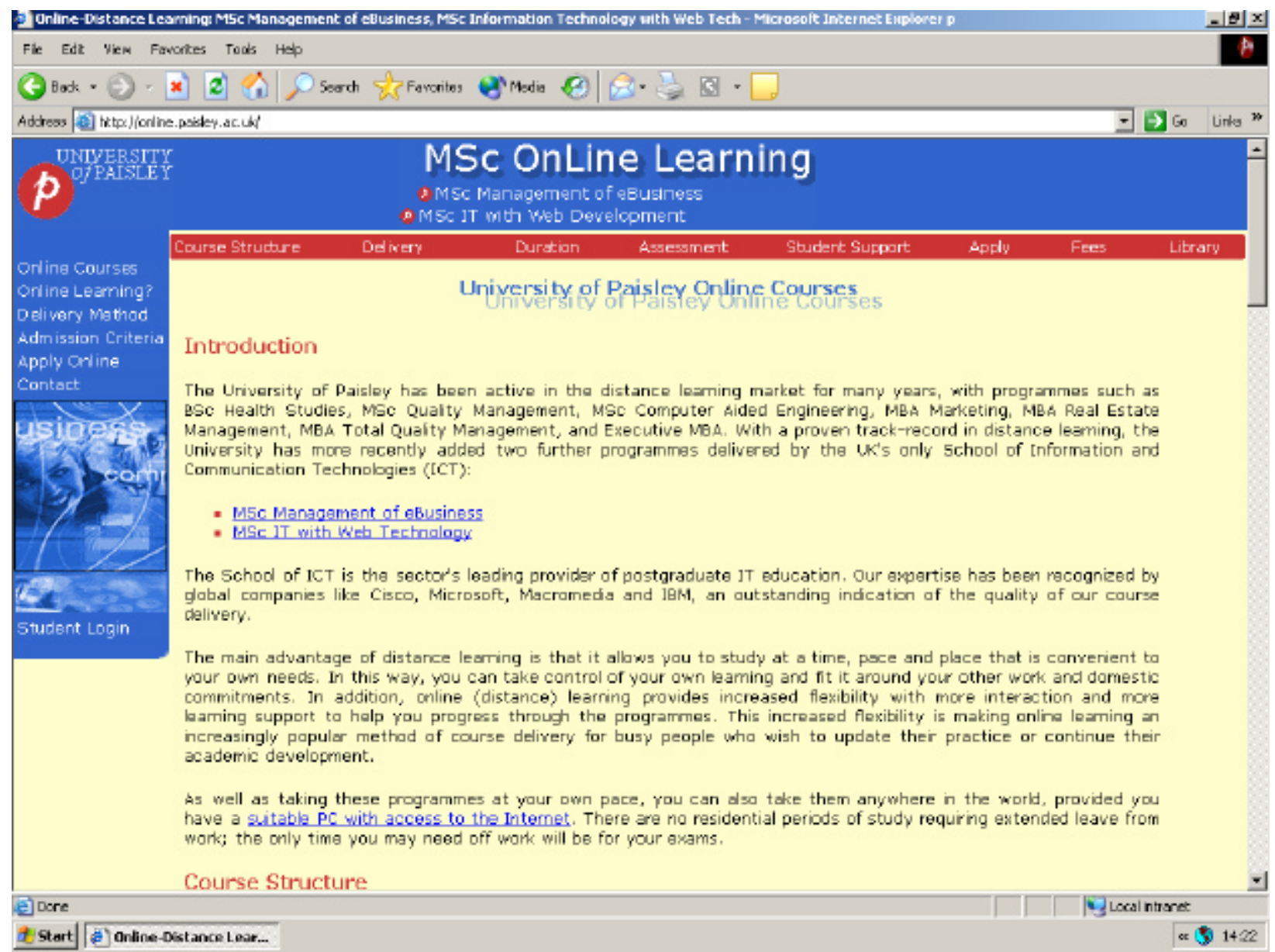

Figure 2: The online learning home page

The Management of eBusiness course is hosted via the FirstClass learning environment. All course and conference materials are posted in First Class, and course administrative business is conducted from within FirstClass. (Figure 2 shown the on-line learning home page.) At the moment the Management of eBusiness course utilises the FirstClass conferencing and mail facilities, but it is hoped to make use of the chat facilities in the future.

\section{Flexibility}

The Management of eBusiness course has been so designed as to be flexible in terms of learner access. It is independent of both place and time (with the exception of scheduled revision tutorials) and offers variety in the way that learners can make use of the course materials. Learners are encouraged to be independent and to take responsibility for their own learning. Learners can access the module materials in whatever order they choose, decide for themselves what they will learn within a topic area and progress through the materials at their own pace. Some learners with prior knowledge may not have to study all the materials in depth, while others may have to apply themselves assiduously to grasp all the concepts.

\section{Interactivity}

The following activities indicate how the Management of eBusiness course provides interactivity. The teacher provides several planned or spontaneous opportunities for sharing ideas, opinions, and beliefs in pairs or in small groups. This occurs in the weekly tutorials, when learners answer tutorial questions, raise and discuss issues and comment on each other's contributions. At present learners are not split into 
groups for collective work, but it is intended in the future to form groups to promote collaborative and group working.

Learners can be required to work together to produce a paper or a report summarizing information and share the findings with the class. At present tutorial conferences require learners to comment on a case study or an article from a journal. Learners are encouraged, but not required, to work collectively on these tasks. Learners are expected to make use of the discussion forum for planned discussions and exchanges of information. This occurs in weekly tutorials and in the learners' private discussion forum. Learners are also expected to initiate communication with the teacher or fellow learners. Learners communicate with the teacher and with fellow learners on a voluntary basis, there being no requirement to do so.

\section{Learner Control}

Learner control is the degree of control that learners are able to exercise over the activity of learning in terms of pace, depth of study, content range, type of media accessed and time spent studying. The design, content and assessment elements of the course materials must all be controlled by the course designer. The asynchronous learning environment created for the Management of eBusiness course provides additional elements designed for remote successful learner control.

The online menu system allows the course materials to be flexible, easily accessible, and instantly recognisable to learners. The menu has a hierarchical structure, each module being divided into sections. These sections are further divided into sub-sections and sub-sub-sections. Learners can move from page to page within each section and each sub-section, and there are navigation buttons on each individual screen to allow movement between sections and sub-sections. The same menu structure is used for each of the modules of the course. This means that all the course materials have a consistent navigational structure. Learners soon become familiar with the menu structure and navigate confidently through the course materials without becoming lost or disorientated. The menu system incorporates a place-marker feature so that when learners click on a button in the menu, the button changes colour. This gives learners a clear reference in the menu to indicate which section of the module they ha ve accessed.

\section{Content}

The learning objectives and learning outcomes for the course modules are precisely stated, so that learners know exactly the degree of understanding they have to achieve and the level of knowledge required to successfully complete the course.

The course materials are presented on a variety of screens. Some of these are solely text-based, some are text-based with diagrams, some are interactive with animations, some are demonstrations and some have exercises and self-tests, the last in the form of an online multiple-choice quiz. All of these require learners to interact with the materials to produce the desired results. Information resources are, where possible, hyperlinks to electronic versions of books, journal and newspaper articles and reviews and other relevant web-based resources. Where materials are not available electronically, learners can be supplied by post with books and articles available in the University Library.

The e-workbook is available in FirstClass and is designed to be used alongside the full-text version of the course materials. The e-workbook contains a summarized version of the course materials and is a carefully tailored, accurate version of the full text. The materials are couched in language familiar to learners, which allows them to work through the basic concepts using the interactive elements, and gives them time for reflection and consideration. Learners have a wide variety of screens to work from in the e-workbook and each screen incorporates learning activities. Learners should be able to acquire a full understanding of the course materials from the e-workbook and the evaluation has shown that many 


\section{Evaluation into the Role of Online Learning}

learners answer the self-assessment questions and complete the exercises and activities. The e-workbook is graphically-rich and employs diagrams and illustrations to aid learner understanding and information retention. Information is presented in a visual format to highlight important concepts and ideas and to encourage learners to make and retain associations. Interactive exercises entail learner response and involve intellectual effort so that the learner is actively involved in the overall process.

The Management of eBusiness course offers learners a choice of using either the full text version of the course materials, available in the .pdf file format for easy printing, or the accompanying summarised, graphic-rich, interactive web-based version, available in the e-workbook, or a combination of both. It was recognised early on in the design stage of the course that learners would probably wish to have a facility to enable them to print out the course materials. Being portable, the printed form of the materials allows for reading away from the computer screen, it being undesirable for learners to be reading text from a screen for long periods of time. It was also considered desirable that learners have a full- text version of the course materials available to them.

\section{The Interactivity}

The learner can go over each step and complete exercises in order to verify that everything is fully understood before going on to apply the newly acquired skills and techniques. An important factor in the learning process is that learners are made aware of the associations between ideas. If the associations between ideas are not made clear to the learners, they may assimilate and memorise facts and learn only what applies in specified circumstances instead of being able to utilise their newly acquired knowledge more widely in other relevant situations. The use of interactive materials can provide learning activities that promote understanding of concepts by taking learners through the concepts in incremental steps. They can then practise what has been learnt and apply the new knowledge to different sets of circumstances. Interactivity within the course materials of the Management of eBusiness course is contained primarily within the screens of the e-workbook and takes a variety of forms. These are animations, demonstrations with exercises, and animations with questions. An example is shown in Figure 3.

Demonstrations and exercises are also included in the e-workbook's screens. Demonstrations explain by means of easy-to-follow stages how a concept is built up. Each stage is fully described so that learners know what they are doing and why. Demons trations also provide further examples of the concept, with the examples becoming increasingly more complex and with exercises for learners to complete to test their understanding. The navigation buttons on the screens allow learners to replay the demonstration either in whole or in part. Learners can print out any of the screens to provide themselves with a hard copy of the material.

Learning tasks enable learners to test themselves to ascertain whether they have understood the techniques and can apply the m. It is important that learners understand that the concepts have a wide application, and also that the exercises are designed to cover a variety of situations. Learning tasks can take the form of set exercises for learners to complete or can involve tasks requiring learners to reflect on what has been learnt.

\section{Questions, Feedback and Assessment}

It is important for learners to be sure that, through appropriate performance on their part, the desired learning has occurred. This entails an assessment of the learning outcome and an evaluation of the extent of its success. Assessment criteria and methods must be closely aligned to the stated learning outcomes to meet learners' reasonable expectations of the kind of performance that is required of them. 


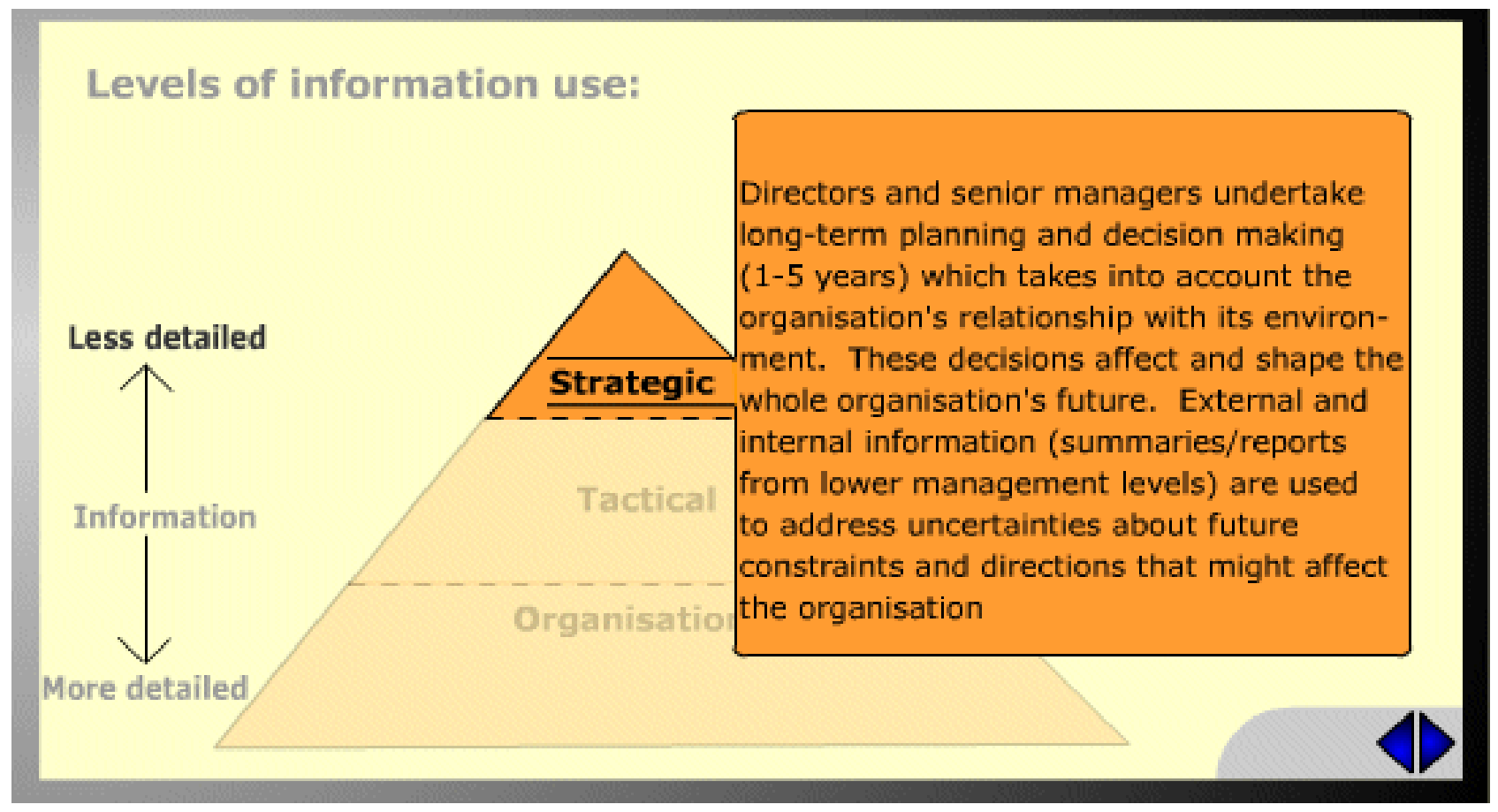

Figure 3: An example of animation within the course content

In the context of the Management of eBusiness course, use is made of both multiple-choice questions and short-answer questions. The objective of the multiple-choice quiz is twofold: it allows learners to check their knowledge and understanding of the course unit materials, and supplements the self assessment questions. The multiple-choice questions are written in clear and precise language, have highquality content and have only one correct answer. On completion of a question learners can choose whether or not to turn to the correct answer, with its explanation of why that answer is correct. The results of the quiz are not recorded and learners can attempt the questions as often as they like. Where questions are wrongly answered explanations are provided, which allows the learner to move on to the next learning task without having to consult the course materials further to correct their mistake.

The self-assessment questions are short-answer questions designed to elicit a specific answer from the learner. Learners cannot guess what the right answer is or rely on partial knowledge. Learners can attempt a question and, if they are confident that their knowledge is sufficient, can choose to access the answer immediately. However, if they are unsure about their level of knowledge learners are advised to undertake further study before looking at the answer. The questions are designed primarily to encourage learners to consider in detail the concepts and ideas in the course materials.

They are also intended to develop a deep approach to learning and to encourage learners to reflect on what has been learnt. In addition, they help learners to check their understanding of the course materials, as well as acting as a revision aid by highlighting and expanding upon important elements of the course. The questions also aim to reinforce learning by providing further in-depth explanations of difficult concepts.

It is essential that learners are given detailed comments and feedback on work they have completed. The self-assessment questions allow learners to choose for themselves when to view the answers and feedback can be immediate or delayed at the learner's discretion. Learners should be given feedback on their assignments as soon as possible after marking, so that they can evaluate their work in the light of the tutor's comments and consider any suggestions made. Feedback should include comments on omissions, irrelevancies, style and presentation (when appropriate) as well as an analysis of mistakes. There should also be an accompanying commentary so that learners can take steps to improve their performance. In 
the Management of eBusiness course it was decided not to assess learners' contributions to the online tutorials. It was thought that learners were being sufficiently assessed on the basis of their existing assignments and examinations and that to introduce a further assessment element would be excessive.

\section{The Conferencing}

The weekly online tutorial is a central element of the Management of eBusiness course and is a feature of every module. The tutorials have a formal structure, with learners being required to respond to a task set by the teacher. The tutorials take various forms, as for example questions and exercises, case study examinations and web-based research. When the tutorial takes place in the discussion group format, learners are required to read a prescribed section of text, an article from a journal or a feature in a newspaper which is relevant to their current topic of study and to respond in turn to questions set by the teacher.

The aim of the discussion is to promote meaningful dialogue among learners and also between learners and the teacher. Learners are encouraged to contribute to the discussion, to comment on the contrib utions of fellow learners and to open up further lines of debate. The aim of the activity within the group is to generate lively discussion, which in turn elucidates the issues being considered and encourages deep learning. Conferencing is attractive to learners irrespective of their favoured learning style.

Case study discussions involve the teacher in gathering information about an event, problem or process, making the information obtained available online and posing questions or requiring learners to comment on specific aspects of the new information. Case study materials can be a useful adjunct to course materials by providing illustrations of central ideas and so adding credence to points raised. If a learner is particularly interested in the subject of a case study, either through personal experience or by being wellinformed about it, the teacher may ask him/her to moderate part of the discussion. This gives learners the opportunity to demonstrate their knowledge of the topic and to determine the direction of the debate and control its course.

\section{Evaluation of the Online Programme Delivery}

Evaluation techniques available as part of an information gathering process to evaluate the effectiveness of the online distance learning environment included analysis of student assessments, use of learner/teacher questionnaires, use of learner/teacher interviews, feedback from people having an indirect link with the instructional system and network data such as usage data and participation data.

\section{Tutorial Conferencing}

The greatest disappointment, in relation to the educational elements was the failure of the tutorial conferencing feature to attract enough contributors to produce an interesting and meaningful discussion. This lack of success was evident with the first cohort of learners and was repeated with the second cohort. Learner response levels at the beginning of each of the modules were irregular, but there were at least some responses. However, these faded away until there were either very few responses or no responses at all, particularly after the date of issue of the courseworks. This was not a satisfactory outcome for either learners or tutors. Those learners who contributed received valuable feedback from tutors, but the tutorials failed to develop into a discussion among learners and developed into a rather sterile question and answer session lacking any opportunity for ideas to be explored and developed in a series of debates. On a positive note, the respondents who had just completed the course all indicated that they would undertake further online study as a result of their experience of the Management of eBusiness course. 
The problems with the tutorial conferencing were two-fold: there were insufficient contributions for a meaningful dialogue between learners to develop and the low level of response and lack of participation meant that teachers had no real gauge of learners' progress on the course. Lack of response occurred notwithstanding the fact that tutorial requirements were made clear from the outset. Learners were welcomed on to the course from its commencement and, despite every effort on the part of the teachers to encourage learners to participate, they failed to so. This was seen by teachers as an undesirable situation.

\section{Dealing with Low Participation Rates}

A number of strategies can be considered in attempting to increase participation rates, such as introducing an assessment element into conferences, or presenting a class test as a tutorial exercise, or a combination of both. Assessing conferences is an attractive proposition, but it is not without its difficulties. Teachers would have to develop assessment criteria that take the following into account:

- Whether contributions to all tutorial conferences are to be assessed? If they are not, learners are likely to respond strategically and only contribute to those that are to be marked. If the teacher determines in advance which tutorials are to be assessed, this may suggest to learners that not all tutorial material is of equal importance or relevance.

- After having contributed compulsorily to all the conferences the question arises should learners be given the opportunity to decide which contributions they wish to be assessed, thereby introducing an element of learner control into the situation? The drawback to this approach is that it may encourage learners to act strategically, in that they may not submit high quality work to certain tutorials, knowing that they can choose which are to be assessed.

- The creation of a marking scheme also presents problems. The aim of tutorial conferencing is to encourage a flow of dialogue between learners, but marking requires a clear set of points for which to award marks. An equitable marking scheme has to be objective. Introducing objective factors into the conferencing environment, where the aim is to encourage discourse and exploration of ideas, would destroy the spontaneous nature of the conferencing environment and its aim of promoting an exchange of ideas. Formulating questions for marking is quite different from asking questions designed to elicit responses in an effort to open up a debate. Formalising the tutorial conference in this way would destroy those elements of dynamism and spontaneity which are germane to good conferencing. The distinction between the aims of tutorial conferencing and the nature of traditional examinable material serves to illustrate one way in which online is a quite different ethos from the face-to-face environment.

Teachers would have to devote a considerable amount of time to marking conferencing tutorial submissions, which would reduce the amount of time available for other tasks associated with the modules. If marks were allocated to tutorial conferencing, this would require a reduction in the amount of marks awarded either for the coursework or the examination element of the module. It may transpire that teachers do not want to alter the coursework or the examination element to accommodate another assessable element in the modules. This does not rule out the assessment of tutorial conferencing in the future, but suggests that, with reference to the Management of eBusiness course, alternative strategies are called for.

\section{Strategic Learners}

From reading the evaluation questionnaires, it is clear that, because of the demands on their time, many online distance learners are of necessity strategic in their approach to learning. This means that they take a conscious decision to apply themselves only to those tasks that count towards the final assessment and, since conferencing is not assessable, it is low on their list of priorities. Which is not to say that learners 
do not wish to take part in tutorial conferencing, but only that they choose to devote themselves to activities that count towards obtaining marks. This despite the fact that by so doing they have no indicator of how they are faring on the course other than through the self-assessment questions in the module materials and the online quiz. Both the self-assessment questions and the results obtained from the online quiz are designed to check basic understanding of the module materials, and differ from tutorial type questions in terms of the degree of analytical thought they call for.

\section{Strategic Teachers}

If the tutorials are not to be assessed for the reasons outlined above then, if learners are adopting a strategic approach to their studies, it is recommended here that teachers themselves should become strategic in their approach to teaching. This is particularly the case with the Management of eBusiness course because of the particular kind of learners taking the course. The se are mature, academically experienced and highly motivated for a variety of reasons. They are able to accurately analyse the assessment requirements of the course and, having competing demands on their time, tend to act strategically. To counter this, means teachers have to devise alternative strategies in relation to the issue of conferencing tutorials. These strategies include:

- The transfer of key elements in module materials to tutorial materials. This ensures that learners must, at the very least, access the conferencing tutorials and read through these key elements in the context of the conference.

- Placing further examples in the conferencing tutorial area in response to learners' requests for more examples to be made available. This draws learners into the conferencing environment and may encourage them to respond to tutorial questions.

- Dividing tutorials up into sections (subject matter permitting) that include questions requiring both short and long answers. This takes into account learners' comments that demands on their time are the biggest single barrier to contributing to tutorials. This would allow learners to concentrate on particular areas where they may have a particular interest or may feel that their understanding is deficient. The evaluation has revealed that learners favour the self-assessment questions, which suggests they may find short answer questions a more attractive prospect than responding to more time-consuming questions requiring longer answers.

Currently, teachers on the Management of eBusiness course, although they are highly experienced lecturers, receive no formal training on the conduct of online tutorials. However, as this course may be their first experience of teaching in an online environment, it is recommended that, before undertaking any online teaching duties, these lecturers are given some instruction on how to moderate online conference tutorials. This should include how to formulate the kind of questions that are best suited to the online format, and how best to maintain participants' interest and encourage non or rare participants to take part. It is further recommended that guidelines be drawn up outlining best practice for tutorial conferencing. The recommendations should include examples of successful conferences. Although this tends to happen on an informal basis, plans are currently underway to formalise this training process as the number of online learning courses increase.

\section{Conclusion}

The MSc Management of eBusiness is now entering its third year of delivery in online learning mode. Although the points highlighted in the previous section are important issues that need to be addressed by the course team, student feedback has been consistently supportive. Creating an environment with high levels of teacher/learner and learner/learner interaction is a challenging task. Experienced learners studying strategically because of limited time may have less interaction with others since, being largely self- 
sufficient, they may simply have no reason to contact either other learners or the teacher except about, say, coursework or examinations. The 'community of learners', to which Harasim et al., (1995) refer, has proved an elusive model to create in the Management of eBusiness course because of the kind of learners involved and because the course does not include many collaborative or group activities to foster a co-operative spirit. It is recognised that not all modules are suitable for collaborative working. However, it is recommended that, where materials lend themselves to collaborative and group activities, learners are encouraged to participate in them as a way of creating a 'community of learners'.

It is important that teachers acquire the skills necessary for successful teaching in the online environment. Learners must have a good reason to access the tutorial conferences, and the recommendations made are an attempt to lend credence to tutorial conferencing without introducing an element of compulsion. Knowing the kind of learner taking the course allows the tutor to adopt teaching strategies appropriate to the particular circumstances of that learner. The strategic approach to teaching is not aimed at penalising learners who do not interact with others or who fail to contribute to conferencing, but is an attempt to ensure that learners contribute to all the elements in the course and so prevent it becoming what is in effect little more than an electronic correspondence course. These are important lessons that need to be addressed by all online learning developers and academics if online learning is to deliver the ample benefits outlined in this paper and enrich the student learning experience.

\section{References}

Biggs, J.B. (1979). Individual differences in study processes and the quality of learning outcomes, Higher Education, 8. 381394.

Ellington, H., Percival, F. \& Race, P. (1983). A handbook of educational technology. London: Kogan Page.

Entwistle, N. \& Ransden, R. (1983). Understanding student learning. London: Croon Helm.

Entwistle, N. (1997). Contrasting perspectives on learning. In The Experience of Learning: Implications for Teaching and Studying in Higher Education (Ed) Marton, F., Hounsell, D. \& Entwistle, N. Scottish Academic Press

Feenberg, A. (1998). Distance learning: Promise or threat? www.rohan.sdsu.edu/faculty/feenberg/TELE3.HTM

Grant K., Stansfield, M.H. \& Land, R. (2000). Teaching information management to honors degree students: The information challenges approach. Informing Science, 3, 2. 41-46.

Harasim, L., Hiltz, S., Teles, L. \& Turroff, M. (1995). Learning networks. A field guide to teaching and learning online. MIT.

Kolb, D.A. (1984). Experiential learning - experiences as the source of learning and development. Englewood Cliffs: Prentice-Hall.

Marton, F. \& Säljö, R. (1976). Approaches to learning. In The Experience of Learning: Implications for Teaching and Studying in Higher Education (Ed) Marton, F., Hounsell, D. \& Entwistle, N. Scottish Academic Press

Marton, F., Hounsell, D. \& Entwistle, N. (1984). The experience of learning. Scottish Academic Press.

Säljö, R. (1979). Learning about learning, Higher Education, 8, 443-451

\section{Biographies}

Evelyn McLellen is a teaching fellow in the School of Information and Communication Technologies at the University of Paisley. Her interests are in the field of e-learning and she has recently completed her MSc in this field and is now embarking on a PhD which explores the role of e-learning in enhancing study skills of students in making the progression from pre-university to university level education.

Mark Stansfield is a lecturer in the School of Information and Communication Technologies at the University of Paisley and is Programme Leader of the MSc Management of eBusiness. He has a PhD in Information Systems and has published papers on information systems and e-business in a number of in- 


\section{Evaluation into the Role of Online Learning}

ternational journals. Main research and teaching interests include e-business, e-commerce, m-business, e-learning and information systems development. Mark is also the Reviews Editor of the International Journal of Information Management. 